\title{
LADO PREFERIDO DA MASTIGAÇÃO. ACASO OU OCLUSÃO?
}

\author{
THE PREFERED CHEWING SIDE. HAZARD OR OCCLUSION?
}

\author{
Maitê André Camargo \\ Alessandra Christine Santana ** \\ Antonio Alberto de Cara ${ }^{* * * * *}$ \\ Maria Inez Roda *** \\ Rodrigo Otávio Di Nápoli Melo *** \\ Savério Mandetta ${ }^{* * * * * *}$ \\ Claudia Inês Capp ${ }^{* * * * * * *}$
}

\section{RESUMO}

A atividade mastigatória é extremamente complexa. Envolve movimentos rítmicos da mandíbula, sob controle do sistema nervoso central e modulaçôes de impulsos sensoriais periféricos, com a finalidade de trituraçáo do alimento preparando-o para a deglutiçáo. O posicionamento dos dentes nos arcos e o relacionamento funcional das faces oclusais antagonistas são extremamente importantes no desempenho dessa atividade. Pode-se supor, portanto, que eventuais desarmonias oclusais possam interferir negativamente no funcionamento adequado do sistema mastigatório. $\mathrm{O}$ presente trabalho objetiva realizar uma revisão da literatura a respeito da fisiologia da mastigaçáo e o efeito das desarmonias oclusais sobre um importante aspecto funcional, o lado preferido de mastigaçáo. A maioria dos autores pesquisados considera que desarmonias oclusais alteram os padróes de normalidade na função mastigatória. A preferência por determinado lado de mastigação parece ter relação direta com a melhor qualidade de relacionamento oclusal no referido lado. Não obstante, em alguns casos, pode existir uma adaptação funcional às desarmonias oclusais, possibilitando que a mastigação seja realizada sem inconveniências, através de mecanismos compensatórios.

DESCRITORES: Oclusão dentária - Mastigação

\section{ABSTRACT}

The masticatory activity is complex and involves rhythmic mandibular movements under central nervous system control and peripheral sensorial impulses, to aim the food trituration to prepare it to the deglutition. The teeth site on the dental arch and its relationship with the antagonist is one of the agents directly involved in this activity performance. Therefore, eventual occlusal disorders could interfere on the masticatory system performance. The aim of this work is to review the literature about mastication physiology and the result of the occlusal disorders on the important functional aspect: preferred chewing side. Most of the researchers believe that occlusal disorders alter the masticatory standard function. It would be a functional adaptation through a compensatory mechanism that allows a person with occlusal disorders to accomplish the masticatory function in a satisfactory and comfortable way.

DESCRIPTORS: Dental occlusion - Mastication

\footnotetext{
* Doutoranda em Dentística na Faculdade de Odontologia da USP maiteandre@usp.br

** Professora Assistente de Prótese da Universidade Bandeirante de Sáo Paulo - UNIBAN.

*** Mestres em Dentística pela Faculdade de Odontologia da USP

**** Prof. Doutor do Departamento de Dentística da Faculdade de Odontologia da USP

***** Livre-Docente pela FOUSP e Prof. do Programa de Pós-Graduação em Ortodontia da Faculdade de Odontologia da UMESP

****** Doutora em Dentística pela Faculdade de Odontologia da USP
} 


\section{INTRODUÇÃO}

O sistema mastigatório é extremamente complexo em virtude da variedade de estruturas envolvidas: ossos, músculos, ATM, dentes e suas estruturas de suporte. Para a sua perfeita função, é necessário que exista harmonia entre as unidades funcionais formadoras do sistema e ausência de fatores que limitem a precisão e dinâmica dos movimentos. Tudo isso coordenado por um controle neurológico altamente refinado.

Sabe-se que a atividade fisiológica fundamental de mastigação depende, entre outros fatores, do posicionamento dos dentes nos arcos dentais e seu relacionamento com dentes antagonistas. Parece lógico, portanto, inferir que eventuais desarmonias na oclusão possam influir sobre tal atividade básica.

O relacionamento da oclusão com distúrbios de funcionamento do sistema mastigatório tem sido alvo de estudo por diversos pesquisadores, especialmente em relação aos problemas envolvendo a articulaçáo têmporomandibular. No entanto, estudos a respeito da oclusão em desarmonia e seu efeito sobre padróes mastigatórios funcionais são pouco freqüentes.

O objetivo do presente trabalho é realizar uma revisão da literatura no que concerne à normalidade e anormalidade da função mastigatória, relacionando-a com a oclusão.

\section{REVISÃO DA LITERATURA}

\section{Fisiologia da mastigaçáo relacionada à oclusáo}

O comportamento mastigatório é uma das mais complexas funções do ser humano, sob controle do sistema nervoso, porém influenciado pelos dentes e morfologia da ATM (Yamashita et al. ${ }^{14}, 1999$ ).

Quando se pensa em atividade mastigatória normal, dois conceitos importantes devem ser estabelecidos: ciclo mastigatório e eficiência mastigatória. Chama-se ciclo cada golpe mastigatório partindo da MIC e voltando a ela. O padrão normal deve alternar o lado de trabalho e deve ter o maior número de ciclos com contatos dentais. A eficiência mastigatória é caracterizada pela quebra de alimentos com o mínimo esforço e máximo padrão de redução de tamanho da partícula alimentar. O número de mastigaçóes e/ou tempo gasto para mastigar antes de engolir refletem a eficiência mastigatória (Simóes ${ }^{10}$, 1988).

A duração e as forças desenvolvidas no movimento mastigatório variam de acordo com o indivíduo e o tipo de alimento mastigado, mas o número médio de movimentos mastigatórios é razoavelmente constante para o mesmo indivíduo. Pacientes com eficiência mastigatória reduzida mastigam mais tempo, mas ainda assim engolem partículas grandes de alimento (Wilding ${ }^{12}, 1993$ ).

\section{A mastigaçáo pode ser dividida em distintas fases:}

Incisão, esmagamento e diminuição do tamanho das partículas do alimento, trituração do alimento como preparatório para a deglutição

A mastigação se inicia quando a mandíbula se move para frente e incisa o alimento. $\mathrm{O}$ alimento é então posicionado no interior da boca e a partir daí começa o ciclo mastigatório com a abertura da boca $(16$ a $20 \mathrm{~mm})$ e deflexão lateral (3 a $5 \mathrm{~mm}$ ), que ocupam $35 \%$ do ciclo. A mandíbula, entáo, gira para o lado de trabalho e penetra o bolo alimentar, fase que ocupa $12 \%$ do ciclo. Começa, a seguir, o fechamento comprimindo o alimento durante $28 \%$ do ciclo. Durante a fragmentação ocorre o primeiro contato dentário, que se dá no lado de balanceio de maneira infinitamente leve, suave e rápida (Simóes ${ }^{10}$, 1988). Pouco depois, se iniciam os contatos do lado de trabalho, com aumento gradativo da força muscular até MIC, onde há pausa antes de iniciar novo ciclo (Glickman et al. $\left.{ }^{4}, 1974\right)$.

Existem, portanto, contatos dentais durante a mastigação, mais freqüentemente durante o movimento de deslize, no qual direção e origem são variáveis (Woda et al. $\left.{ }^{13}, 1979\right)$. Entretanto, até a redução adequada dos alimentos, ou seja, nos primeiros ciclos mastigatórios, ainda não existem contatos interoclusais, mas a arquitetura do ciclo é a mesma durante toda a mastigação (Simôes ${ }^{10}$, 1988).

Em relação às estruturas anatômicas envolvidas nos contatos dentais durante os movimentos excursivos, observa-se que o movimento lateral de trabalho é primordialmente guiado pelo deslize das vertentes internas das cúspides vestibulares superiores (predominantemente as mesiais) contra as vertentes externas das cúspides vestibulares inferiores (predominantemente distais). Podem ocorrer, ainda, no lado de trabalho contatos nos molares entre as vertentes externas das cúspides linguais superiores e as vertentes internas das cúspides linguais inferiores. Contatos no lado de balanceio também podem ocorrer de forma fisiológica entre as vertentes internas das cúspides palatinas superiores e as vertentes internas das cúspides vestibulares inferiores, desde que sejam suaves, isto é, desde que não interfiram nos contatos do lado 
de trabalho e, conseqüentemente, no ciclo mastigatório (Mandetta $^{6}$, 1994).

Segundo Dawson ${ }^{3}$ (1988), a extensão para a qual os contatos funcionais desviam da MIC depende da ausência de interferências oclusais restritivas, da consistência do alimento a ser mastigado e da fase do ciclo mastigatório. Ramfjord e $\mathrm{Ash}^{9}$ (1996), no entanto, afirmam que existe recente evidência de que a freqüência de contatos laterais não seja significativamente alterada pelo tipo de alimento que está sendo mastigado e que a mordida forte é mais confortavelmente realizada perto da MIC do que em posiçóes laterais ou protrusiva da mandíbula. Esses autores afirmam que a dentição passa por um processo de adaptação contínua, sofrendo mudanças na tentativa de manter a harmonia fisiológica do sistema mastigatório através de toda a vida do indivíduo. A mastigação bilateral, alternada e multidirecional é o padrão ideal para estimulação de todas as estruturas de suporte, para estabilidade da oclusáo e para limpeza dos dentes. Embora a mastigação possa ser realizada com movimentos unilaterais, ou mesmo com ausência de movimentos laterais, isso não constitui função oclusal ideal (Mandetta ${ }^{6}$, 1994).

\section{Lado preferido de mastigaçáo:}

A revisão da literatura revela uma preocupação dos autores em determinar a relação entre condiçóes oclusais e lado escolhido pelo paciente para mastigar os alimentos com maior conforto. Bates e Stafford ${ }^{1}$ (1975) consideram que, comumente, o paciente mastiga do lado que apresenta maior número de contatos oclusais durante as excursóes laterais.

Helkimo et al. ${ }^{5}$ (1978) mostraram que a qualidade dos contatos oclusais influencia a eficiência mastigatória, e que provavelmente a escolha por um lado preferido de mastigação seria influenciada pela qualidade e quantidade de contatos oclusais daquele lado.

Estudando a relação das condiçóes oclusais com o lado preferido de mastigação, Pond et al. ${ }^{8}(1986)$ concluíram que mordida cruzada, presença de prótese parcial fixa, dentes posteriores sem contato em MIC, interferências no lado de trabalho ou balanceio, contatos abertos, mobilidade dental, sensibilidade ao ar ou percussão não têm correlação com lado preferido de mastigação. Sintomas de disfunção mandibular como sons na ATM, dificuldade de abertura ou mastigação, fraca amplitude de movimento, desvio em abertura ou fechamento, dor muscular ou na ATM, também não tiveram correlação com lado preferido de mastigação. Também Wilding et al. ${ }^{11}{ }^{1}(1992)$ encontraram ausência de associação entre preferência por um lado de mastigação e a área de contato funcional na dentição humana.

Ao se movimentar a mandíbula para direita e para esquerda, ocorre o aumento da dimensão vertical do lado para o qual a mandíbula se movimenta. Segundo Planas ${ }^{7}$ (1988), o indivíduo mastiga de ambos os lados quando os aumentos da dimensão vertical forem aproximadamente iguais dos dois lados. Se o aumento da dimensão vertical for muito maior de um lado, o lado preferencial da mastigação é o que tem menor aumento de dimensão vertical, por ser mais confortável e mais adequado, por possibilitar menor esforço para o paciente.

Uma das conseqüências de desarmonias oclusais pode ser a mastigação unilateral, ou seja, a mastigação passa a ser realizada, inconscientemente, pelo paciente do lado mais confortável, isto é, do lado sem interferências oclusais (Mandetta ${ }^{6}$, 1994; Ramfjord e Ash ${ }^{9}$, 1996). No lado não utilizado na mastigação ou existem interferências oclusais no lado de trabalho ou balanceio e/ou as guias laterais do lado de trabalho estão muito mais inclinadas em relação às guias do outro lado. A restrição da mastigação, se prolongada, poderá ocasionar desarmonia oclusal crescente por mudanças das posiçóes dentais e desgastes desiguais nos dois lados.

\section{DISCUSSÃO}

Grande divergência de opiniōes ocorre em relação aos fatores que influenciam o lado preferido de mastigação.

Segundo Ramfjord e Ash ${ }^{9}$ (1996), uma oclusão em harmonia passa por um processo de adaptação contínua ao longo da vida de um indivíduo, sofrendo variaçóes na tentativa de manter preservada a fisiologia do sistema mastigatório. Esse processo de adaptação, segundo Carlsson et al. ${ }^{2}$ (1979) estaria diretamente relacionado com o sistema neuromuscular, mostrando que muitos indivíduos conseguem se adaptar bem à presença de interferências oclusais. Ainda segundo esses autores, a mastigação bilateral, alternada e multidirecional seria o ideal para a estimulação de todas as estruturas de suporte e para a estabilidade da oclusão. A mastigação poderia até ser realizada com movimentos unilaterais, ou mesmo não laterais, mas isto não constituiria função oclusal ideal. De acordo com essas afirmaçóes, alguns autores se empenharam em estudar o que levaria à mastigaçáo unilateral ou determinaçáo de um lado preferencial de 
trabalho (Battes e Stafford ${ }^{1}$, 1975; Helkimo et al. ${ }^{5}$, 1978; Mandetta $^{6}$, 1994; Planas ${ }^{7}, 1988$; Pond et al. ${ }^{8}, 1986$; Wilding et al. $\left.{ }^{11}, 1992\right)$.

Planas $^{7}$ (1988) elaborou um método de determinação do lado preferencial de trabalho. Segundo este autor, ao movimentar-se a mandíbula para a direita e para a esquerda, sempre se verifica um aumento de dimensão vertical, que quando ocorre igualmente em ambos lados indica mastigação bilateral. Se o aumento de DV não for igual, o lado de preferência da mastigação será o que tem menor aumento, sendo assim o mais eficiente.

A escolha do lado preferido de mastigaçáo seria influenciada pela melhor qualidade e maior quantidade de contatos oclusais daquele lado (Battes e Stafford ${ }^{1}, 1975$; Helkimo et al..$^{5}$, 1978). Porém, opondo-se a essa idéia, autores como Wilding et al. ${ }^{11}(1992)$ não encontraram qualquer relação entre área de contato funcional e preferência por um lado de mastigação. Pond et al. ${ }^{8}$ (1986) foram além, afirmando que mordida cruzada, presença de prótese parcial fixa, dentes posteriores sem contato em OC, interferências no lado de trabalho ou balanceio, contatos abertos, mobilidade dental, sensibilidade ao ar ou percussão, disfunção mandibular, dificuldade de abertura ou mastigação, fraca amplitude de movimento, desvio de abertura ou fechamento e dor muscular ou na ATM não têm correlação com lado preferido de mastigação. Algumas dessas conclusóes contrastam com os achados de Mandetta ${ }^{6}$ (1994), para quem o lado náo utilizado na mastigação deve apresentar interferências oclusais e/ou guias laterais muito inclinadas em relação ao outro lado, o que poderia restringir os movimentos de mastigação. Também para Ramfjord e Ash9 (1996), cúspides proeminentes têm capacidade de restringir os movimentos laterais normais, levando ao desenvolvimento de uma mastigação com trajeto de fechamento em OC. Simóes ${ }^{10}$ (1988) ainda acredita que a criação de interferências oclusais já na dentição decídua pode provocar e perpetuar situaçóes patológicas como mordida cruzada unilateral.

$\mathrm{Na}$ realidade, desarmonias oclusais parecem interferir diretamente na função mastigatória do indivíduo, podendo conduzir a padróes de mastigação unilateral. Entretanto, não se pode negar que oclusôes ditas "não normais" são achados mais freqüentes do que as próprias queixas quanto à função mastigatória. Ou seja, é provável que a capacidade de adaptação do sistema neuromuscular supere o problema oclusal e permita ao indivíduo mastigar confortavelmente.

\section{CONCLUSÕES}

Com base no levantamento bibliográfico e na opinião dos diversos autores estudados, parece lícito concluir que:

Apesar das divergências de opinióes sobre a influência de fatores oclusais na fisiologia da mastigação, a maioria dos autores considera que desarmonias oclusais alteram os padróes de normalidade;

A preferência por determinado lado de mastigação parece ter relaçáo direta com a melhor qualidade de relacionamento oclusal no referido lado;

Pode existir uma adaptação funcional do sistema mastigatório, através de mecanismos compensatórios fisiológicos. 


\section{REFERÊNCIAS}

1. Bates JF, Stafford GO, Harrison A. Masticatory function - a review of the literatures. The form of the masticatory cycle. J Oral Rehabil 1975; 2(3):281301.

2. Carlsson GE, Ingervall B, Kocak G. Effect of increasing vertical dimension on the masticatory system in subjects with natural teeth. J Prosthet Dent 1979 Mar; 41(3): 284-9.

3. Dawson P. Oclusão dentária. Traduzido por Milton Edson Miranda. São Paulo: Quintessence, 1988, $158 \mathrm{p}$.

4. Glickman I, Haddad AW, Martignoni M, Mehta N, Roeber W, Clark RE. Telemetric comparison of centric relation and centric occlusion reconstructions. $J$ Prosthet Dent 1974; 31(5): 527-36.

5. Helkimo E, Carlsson GE, Helkimo M. Chewing efficiency and state of the dentition. Acta Odonol Scand 1978; 36(1): 33-41.

6. Mandetta S. Causas da mastigação unilateral e importância do ajuste oclusal das guias laterais na sua correção. Rev Paul Odontol 1994; 16(1): 18-20.

7. Planas P. Reabilitação Neuro-Oclusal Traduzido por Wilma A. Simões. Rio de Janeiro: Medsi, 1988, 7-79.
8. Pond LH, Barghi N, Barnwell GM. Occlusion and chewing side preference. J Prosthet Dent 1986; 55(4): 498-500.

9. Ramfjord S, Ash MM. Oclusão. Traduzido por Milton Edson Miranda. 4 ed, Rio de Janeiro: Guanabara Koogan, 1996.

10. Simões WA. Ortopedéa funcional de los maxilares. Traduzido por Rosita Colina. Caracas: Ediciones Isaro, 1988 t.1, p.107-130, 397.

11. Wilding RJC, Adams LP, Lewing A. absence of association between a preferred chewing side and its area of functional occlusal contact in the human dentition. Arch Oral Biol 1992; 37(5): 423-8.

12. Wilding RJC. The association between chewing efficiency and occlusal contact area in man. Arch Oral Biol 1993; 38(7): 589-96.

13. Woda A, Vigneron P, Kay D. Nonfunctional and functional occlusal contacts: a review of the literature. J Prosthet Dent 1979; 42(3): 335-41.

14. Yamashita S, Hatch JP, Rugh JD. Does chewing performance depend upon a specific masticatory pattern? J Oral Rehabil 1999; 26(7): 547-53.

Recebido em: 14/09/2006

Aceito em: 16/06/2007 